This is the peer reviewed version of the following article: Jiménez L, Antolín-Suárez L, Lorence $B$, Hidalgo V. Family education and support for families at psychosocial risk in Europe: Evidence from a survey of international experts. Health Soc Care Community. 2018; 00:1-10. , which has been published in final form at https://doi.org/10.1111/hsc.12665. This article may be used for non-commercial purposes in accordance with Wiley Terms and Conditions for Use of SelfArchived Versions. 


\section{Family education and support for families at psychosocial risk in Europe: evidence from a survey of international experts}

\begin{tabular}{|r|l|}
\hline Journal: & Health \& Social Care in the Community \\
\hline Manuscript ID & HSCC-OA-18-0084.R3 \\
\hline Manuscript Type: & Original Article \\
\hline Keywords: & $\begin{array}{l}\text { Family Support, Parenting Interventions, European and International } \\
\text { Patterns of Social Care, Child Welfare, Evidence-Based Practice, Risk }\end{array}$ \\
\hline \multicolumn{2}{|l}{} \\
\hline
\end{tabular}

SCHOLARONE ${ }^{\text {IM }}$

Manuscripts 


\title{
Family education and support for families at psychosocial risk in Europe: evidence from a survey of international experts.
}

\begin{abstract}
There is overwhelming consensus amongst policy makers, academics and professionals about the need to support families in their childrearing tasks. Consequently, European countries have been encouraged to develop family support interventions aimed at guaranteeing children's rights, targeting particularly those children in situations of psychosocial risk. While a certain amount of evidence exists regarding how family support is generally delivered in certain European countries, with a particular focus on parenting initiatives, this paper aims to take existing evidence one step further by providing an updated review focusing on two core components of the Council of Europe's Recommendation on Positive Parenting: families at psychosocial risk as the target population, and family education and support initiatives as the delivery format. The scope of the study was therefore broad, in both geographical and conceptual terms. An online survey was conducted with experts from 19 European countries to gather information regarding how they perceive family education and support initiatives for families at psychosocial risk. Both quantitative and qualitative data were analysed by computing frequencies/percentages and by following a thematic synthesis method, respectively. The results revealed both similarities and disparities as regards provider profiles, intervention characteristics and quality standards. Practical implications are discussed, such as the need to diversify initiatives for at-risk families in accordance with the tenets of progressive universalism, the ongoing need for an evidence-based, pluralistic approach to programmes, and the skills and qualifications required in the family support workforce. This study constitutes a first step towards building a common family support framework at a European level, which would encompass family support and parenting policies aimed at families at psychosocial risk.
\end{abstract}

Keywords: Family support, parenting interventions, European and International Patterns of Social Care, child welfare, evidence-based practice, risk.

\section{Bullet points:}

What is known about this topic:

- Family support varies widely across Europe.

- Recent reports on family support delivery in European countries are available, particularly those focused on parenting initiatives.

- There is a need for an updated European review, with a broader geographical and conceptual scope; there is currently very little specific evidence in relation to families at psychosocial risk as a target population.

What this paper adds:

- Support tends to be provided by local, public welfare agencies, with a multidisciplinary workforce.

- Diversity exists between countries in terms of both target populations and the characteristics of the initiatives themselves.

- Standards concerning cultural validity and manualisation are met, although evidence of effectiveness remains a challenge. 


\section{Introduction}

Since the adoption of the United Nations Convention on the Rights of the Child (United Nations General Assembly, 1989), there has been broad consensus among policy makers, academics and professionals about the need to support families in their childrearing tasks. Parallel to this, increasing social attention has been paid to parental roles and responsibilities. Parenthood is understood today as a social asset, a resource that must be supported and protected due to the crucial role it plays in the development and well-being of new generations (Rodrigo, Almeida, \& Reichle, 2016).

Consequently, European countries have been encouraged to develop family interventions aimed at guaranteeing children's rights, targeting particularly children in situations of psychosocial risk (European Commission, 2013; Council of Europe, 2011). The term 'families at psychosocial risk' refers to those families that fail to meet their children's needs, thereby hindering their development and wellbeing, although these situations are not serious enough to warrant children being placed in out-of-home care (Rodrigo, Byrne, \& Álvarez, 2012). There are several reasons that can lead to psychosocial risk situations for child wellbeing and development, as physical and mental violence, abuse and neglect, as well as abusive or deficient parental practices (Council of Europe, 2011). Despite the variability in such situations, public agencies have a duty to support parents in order to guarantee that children can stay with their birth families, while at the same time ensuring family wellbeing and children's rights. It is important to note that Recommendation $\operatorname{Rec}(2006) 19$ states that local governments are responsible for developing family education programmes aimed at promoting positive parenting, with special focus on psychosocial risk situations (Council of Europe, 2006).

This general increase in sensitivity towards family support in Europe was followed by a global recession that has placed parenting in a more difficult and complex situation, in which many families need and demand support (Molinuevo, 2013). Not surprisingly, several reports describing family support delivery in European countries have been published over recent years (European Social Network, 2012), with particular focus on parenting initiatives (Boddy et al., 2009; Boddy, Smith, \& Statham, 2011; ChildOnEurope, 2007; Janta, 2013; Molinuevo, 2013; Moran, Ghate, \& van der Merwe, 2004). This paper offers a detailed review of this question in Europe from a targetedexpert approach, with families at psychosocial risk as the target population, and family education and support initiatives as the delivery format.

The evidence suggests that there is great diversity in the area of family support at both an inter- and intra-country level (Molinuevo, 2013). Over the past 20 years, different models of family-related services have evolved in different parts of the world. Generally speaking, this has developed along two fronts, through (1) economic support for families, particularly cash payments; and (2) services, especially social, health and psychological services (Daly et al., 2015). In addition to variations in financial support, much diversity has also been found in the way family support services are delivered.

Part of the reason for this diversity lies in forces beyond the field of family support, such as diverse living conditions and national differences in structures, institutions and policy trends across EU countries (Rodrigo et al., 2016). Research in this field clearly indicates that different historical traditions in relation to child welfare policy and practice are associated with differences across countries in approaches to support for parents and families (Boddy et al., 2011). The functional orientations of child welfare systems differ in terms of problem definition, mode of intervention, 
relationship between parents and the state and whether they focus more on child protection (e.g., USA, Canada and the UK) or family services (e.g., Sweden, Denmark, Finland, Belgium, Netherlands and Germany), although there is a growing trend towards incorporating both views (Gilbert, 2012). Furthermore, the family policies adopted by different countries are embedded in a broader philosophy regarding social policies in general, which in turn is strongly linked to the prevailing welfare state model. Some countries have established 'neo-liberal' systems which seek to minimise the role of the state and promote market solutions (e.g., the UK); while others (e.g., Scandinavian countries) have opted for 'social democratic' welfare systems, which seek to redistribute wealth and in which the state assumes most of the responsibility for welfare. Finally, there are also the 'conservative' regimes (e.g., France, Italy and Germany), which fuse compulsory social insurance with traditions of subsidiarity, emphasising social assistance rather than welfare rights (Boddy et al., 2011).

In addition to the diversity that exists between countries as a result of each one's epistemological and organisational context, there is also the diversity of conceptual assumptions and epistemological frameworks in the field of family support itself, which has led to a high level of intra-country diversity. Right from its very beginning, family support research has a plural area, both at a conceptual level and in terms of professional practice. Family support is a frontier-knowledge field, which means it is a very rich area encompassing several traditional disciplines (including social work, psychology, social education and nursing). European reports therefore agree that it should be implemented by a multi-professional workforce (Boddy et al., 2009; Janta, 2013; Molinuevo, 2013), which is why we find a wide variety of different services from different intervention paradigms and in different sectors (Frost, Abbott, \& Race, 2015).

Moreover, only a limited number of countries have specific legislation in this area (Austria, France, Germany, England, Scotland, Belgium and Estonia), and the scope, organisation, delivery and funding of the support provided varies considerably both across and within member states (Janta, 2013). Although there are variations between national and decentralised systems at an inter-country level (Janta, 2013), in general, a large number of intervention bodies are involved at different levels and they tend to be poorly coordinated (Molinuevo, 2013). Some of these bodies are responsible for planning or financing activities, while others are entrusted with the task of implementing the different programmes. The first two activities are generally carried out by both central authorities (e.g., the corresponding Ministries) and local governments, while implementation is normally assigned to local agencies, local services and private organisations, such as NGOs, associations and foundations (ChildOnEurope, 2007).

As well as the aforementioned diversity in family support services, evidencebased programmes have taken on a central role and are being implemented throughout Europe (Daly et al., 2015). These programmes are primarily focused on promoting positive parenting, through the provision of information, skills and support to parents in order to reduce risks and promote protective factors for their children's wellbeing (Moran et al., 2004). Educational programmes are one of the main channels through which parenting support is being developed within and across countries (Daly et al., 2015).

Manualisation constitutes an important quality criterion for evidence-based programmes. This criterion refers to a detailed description of the intervention and its assessment sufficient so that others would be able to implement and evaluate the programme (Flay et al., 2005). For this purpose, an adequate manual should include a 
clear statement of the target population, the causal mechanisms by which the intervention should work, a detailed description of its content and organization, training requirements and orientations, intervention procedures, materials, assessment guidelines, etcetera (Flay et al., 2005; Gottfredson et al., 2015). While some disparity exists between European countries in the manualisation of these programmes (Boddy et al., 2009; Janta, 2013), most large-scale initiatives implemented have a clear format and methodology and well-defined contents and activities (Rodrigo et al., 2016). This high level of standardisation has made evaluation easier (see Moran et al., 2004) and has resulted in the emergence of quality standards designed to gauge the effectiveness of family support programmes (Asmussen, 2011; Axford, Elliot, \& Little, 2012; Flay et al., 2005; Gottfredson et al., 2015). This in turn has led to the adoption of an evidencebased approach to family support, helping to focus currently scarce resources on those programmes that have been proven effective using a scientific methodology (Cartwright \& Hardie, 2012).

In sum, we have a strong body of evidence on how family support is delivered in several European countries, with a particular focus on parenting initiatives. In this paper, however, we take the available evidence one step further with the aim of offering an overview of the current situation regarding family support delivery in Europe, focusing on two core components of Recommendation Rec(2006)19: families at psychosocial risk as the target population, and family education and support initiatives as the delivery format (Council of Europe, 2006). The study therefore aims to answer the following research question: How are family education and support initiatives for families at psychosocial risk being delivered in Europe? In order to provide the best empirical evidence to answer this question, we adopted a broad approach, in both geographical and conceptual terms, carrying out a comprehensive review of European countries by employing a targeted-expert methodology. We also offer a detailed overview of how family support is currently being delivered.

\section{Participants and procedure}

\section{Method}

This study forms part of a larger project aimed at analyzing family education and support initiatives for families at psychosocial risk both in Spain and across Europe. This paper offers an overview of the current situation in Europe.

The study was based on a targeted-expert approach. The selection criteria for participants were: (1) family support as a specialist research area; (2) background in family support policies and services at a national level; (3) lead role in family support research teams; (4) publications on the topic over the last five years; and (5) dissemination of family support-related advances at scientific forums in any European country over the last five years. An initial list of potential participants was drawn up using data from the European Association for Developmental Psychology, and the process followed from then on was a snowball procedure. The study aimed to attain as broad a scope as possible, with representatives from southern, eastern, western and northern Europe. In the end, we contacted 43 experts from 23 European countries: Albania, Austria, Belgium, Croatia, Denmark, England, Finland, France, Germany, Greece, Hungary, Ireland, Italy, Norway, Portugal, Republic of Latvia, Republic of Serbia, Scotland, Spain, Sweden, Switzerland, the Netherlands and Turkey.

Potential participants were recruited via e-mail. Following Dillmann's (2000) recommendations, reminder e-mails were sent two weeks after the initial contact. Specifically, two reminders were sent at two-week intervals. The response rate $(83 \%$, or 
19/23) was very good according to Babbie's (2004) criteria. Figure 1 contains a list of countries that provided information. The number of countries included in the study represents $68 \%$ of the entire European Union.

\section{INSERT FIGURE 1 HERE}

As regards the experts' profiles, it should be noted that $83 \%$ were female. A total of $74 \%$ were affiliated to universities and the rest came from public/private agencies working in the field of child and family support.

\section{The expert survey}

A survey was designed ad hoc to gauge experts' perceptions of the family education and support initiatives for families at psychosocial risk in their respective countries. Questions were designed in accordance with the international quality standards for family support programmes described by Asmussen (2011), Axford et al. (2012), Flay et al. (2005) and Gottfredson et al. (2015). Starting with these components, and considering information availability, an inter-university research team with expertise in family support (Seville, Huelva, Minho, Porto and Faro) agreed on an initial pull of 19 items. In order to provide content validity, two academic experts in the field piloted the survey in Spain and Portugal, and 2 items were added from their feedback. Three further experts from both Spain and Portugal completed the survey independently and the interexpert agreement was calculated for each country. The average Fleiss Kappa for the survey was 1 for the Spanish and 0.92 for the Portuguese experts, according to Randolph's calculation (2008), indicating an excellent agreement rate (Fleiss, 1971). An external English-speaking researcher with a background in psychology research reviewed the final version, and minor adaptations were made to make the questionnaire clear and more colloquial, and to ensure greater precision in the use of family support technicalities.

The final version consisted of 21 items, although only information from 16 of them is provided in this paper. Three of the items were about service provider profiles (including delivery, geographical scope and sector), eight were about intervention characteristics (asking about target population and risk level, format and methodology, practitioner profiles, contents and components, and theoretical model) and five covered quality standards (including evidence-based programmes, manualisation, evidence of effectiveness, cultural validity and partnerships with academia). All items were posed in a multiple-choice format, except for those concerning contents, methodology and the theoretical model, which were formulated as open questions. In relation to the multiplechoice format, it should be noted that all questions required a single response, except for those referring to practitioner profiles and other components of the intervention, which allowed for multiple responses.

\section{Data collection and analysis}

The survey was conducted in English. It was administered online using the Opina online survey software. A web link was sent to the experts via email in order to enable them to complete the survey and the whole process took about 15 minutes. Experts were also provided with a glossary of terms to guarantee inter-expert consistency. For the purposes of this study, family education and support programs were understood as 'those interventions aimed at promoting positive parenting with an educational component. We wish to include both highly-structured programs (e.g., "Triple $P$ Positive Parenting Program") and intervention experiences that are not in a manual but are relatively structured and are implemented by practitioners in family 
preservation services'. Moreover, at-risk families were described as 'those families that are preservation service clients due to parenting difficulties that hinder child wellbeing. However, these situations are not serious enough to require out-of-home placement'. Following the terminology of the Recommendation Rec(2011)12 on children's rights and social services friendly to children and families, preservation services refer to specialised social services that ensure immediate emergency interventions and address negative impacts of adverse childhood experiences, and provide social and psychological support to children and their families (Council of Europe, 2011).

All the data were exported to the SPSS software package vs. 22. Analytical techniques included the computation and further examination of frequencies and percentages for multiple-choice questions. Open questions were analyzed by means of an inductive content analysis. For this purpose, the information was coded using the thematic synthesis method proposed by Thomas and Harden (2008). Three stages were followed: (1) free line-by-line coding of the findings; (2) organisation of these codes into homogeneous areas to build up descriptive categories; and (3) re-interpretation and grouping of these categories to develop final analytical themes. The analytical themes were described using narrative techniques. The information about theoretical models and intervention content was also numerically codified and frequencies and percentages were computed and examined.

\section{Ethical considerations}

All participants took part voluntarily after signing an informed consent form in accordance with the Declaration of Helsinki. The aims of the research project were explained and they were assured that their anonymity would be protected. This study was carried out in accordance with the recommendations made by the ethical committee of the Regional Government of Andalusia.

\section{Results}

\section{Service provider profiles}

In relation to the profile of service providers, participants stated that in their countries most family education and support initiatives for at-risk families were delivered by public agencies $(74 \%)$. The remaining $26 \%$ were provided by organisations in the nonprofit sector (e.g., NGOs, foundations and associations). There was considerable geographical diversity in terms of the agencies responsible for interventions, with $58 \%$ of experts identifying local authorities, $21 \%$ regional ones and $21 \%$ national agencies. There was a certain degree of consensus concerning the sector responsible for delivery, with $74 \%$ of experts coinciding in identifying social services/welfare as the most common; inter-sectorial delivery was the second most commonly-mentioned option $(16 \%)$. Table 1 outlines the service provider profiles by country.

\section{INSERT TABLE 1 HERE}

\section{Intervention characteristics}

Table 2 contains quantitative information about intervention characteristics, again by country. In sum, and in relation to the target population of the interventions, participating experts identified parents as the most frequent target population $(53 \%)$, closely followed by the whole family (32\%). There was a high degree of diversity regarding participants' risk level, with the most frequent option being a medium-high risk level $(42 \%)$. The results also reflected variability in relation to the intervention format, with $58 \%$ rating individual interventions as the most frequent format, and the 
remaining $42 \%$ citing group interventions. The question about practitioner profiles allowed for multiple responses. The results revealed that all profiles were selected to some extent, although together, psychologists and social workers accounted for $84 \%$ of the total (either exclusively or jointly with others). Other intervention components, in addition to the educational one, were explored through a multiple-response question. The results revealed that in addition to the educational component, these initiatives usually include information and guidance $(84 \%)$, as well as therapy or counselling $(58 \%)$.

\section{INSERT TABLE 2 HERE}

As well as quantitative data, 16 experts provided qualitative information about the theoretical models guiding the interventions. Seven analytical themes were extracted from their reports. More than one theoretical approach was usually reported. The results are displayed in Figure 2, which shows that an ecologic-systemic perspective was the most frequently adopted theoretical model (62\%). A mixed-eclectic approach was also frequently reported (44\%), as was a behavioural and/or cognitive approach (44\%). Other answers included a strengths-based perspective $(31 \%)$, attachment and social learning theories $(25 \%)$, and a developmental approach $(6 \%)$. It is worth noting that $31 \%$ of the experts reported that family support interventions were not guided by any theoretical model.

\section{INSERT FIGURE 2 HERE}

Fourteen experts provided qualitative information about the content of the interventions. Nine analytical themes were extracted from their reports. Most agreed on parental practices as the main content $(79 \%)$, referring to parent-child interactions such as discipline practices, communication skills, bonding and conflict resolution. Children's developmental needs were identified as core components by $36 \%$ of experts, along with (albeit less frequently) how to deal with child behaviour problems (29\%) and childrearing and home routines (21\%). For $14 \%$ of experts, social support, life skills and substance abuse in the family emerged as relevant contents. Finally, parenting stress was reported by $7 \%$ of experts. It was also pointed out that the contents depended on specific family strengths and needs (7\%).

The open question about intervention methodologies prompted a wide range of answers that made it difficult to extract analytical themes or establish reliable percentages. In terms of content analysis, some experts referred globally to the format of the initiatives, reporting heterogeneous approaches including individual counselling, group-based methodology, individual therapy, video-supported information, home visits and informative materials. Different answers were also elicited in relation to the methodology used during the intervention, with references to informative, skill-building and experiential approaches. Finally, a diverse range of different techniques were also mentioned, including large group discussions, small group activities, videos, games, role-playing, exercises, sharing of experiences, case studies, use of demonstration materials, narrative-informative sessions and printed material.

\section{Quality standards}

Several quality standards for interventions were included in the study (see Table 3). Most of the experts reported that, in general terms, the interventions did not comply with the criteria of evidence-based programmes $(58 \%)$. However, when evidence-based programmes were available, $77 \%$ of experts mentioned partnerships with universities. The vast majority of the experts agreed that interventions were backed up by 
manualisation (42\%) or at least some written materials (53\%) (jointly 95\%). Moreover, only $21 \%$ of experts reported that the interventions in their country had no evidence of effectiveness in general terms. However, we should not overlook the fact that $68 \%$ of evaluation efforts were labelled as being non-rigorous, meaning reports on client satisfaction or coverage analyses. It is also worth noting that only experts from $10 \%$ of participating countries reported rigorous evaluations as the most common framework. As for the ecological validity of the interventions, $58 \%$ of experts reported programmes designed in their country as the most frequent option; with foreign but culturally adapted ones rated as the most frequent choice by $32 \%$ of experts.

\section{INSERT TABLE 3 HERE}

\section{Discussion}

This study aims to provide an overview of the current situation in Europe concerning family education and support initiatives for families at psychosocial risk. Although it is true that a certain amount of evidence already exists regarding the way family support initiatives are delivered in some European countries, with the focus mainly on parent education programmes (Boddy et al., 2009; Boddy et al., 2011; ChildOnEurope, 2007; Janta, 2013; Molinuevo, 2013; Moran et al., 2004), to the best of our knowledge, this study is the first to focus on families at psychosocial risk as the target population with a broad geographical and conceptual scope.

The information provided by the panel of experts revealed both similarities and disparities in the organisation, scope, delivery and funding of family education and support initiatives for families at psychosocial risk in Europe. The results from the countries that participated in this study are consistent with available European reports on family support services for the general population, in which common elements and diversity at both an inter- and intra-country level have been well documented (Janta, 2013; Molinuevo, 2013).

If we look at similarities, most experts from participating countries identified local public social/welfare agencies as the main delivering institutions. These results highlight two important points. First, most European countries have solid public welfare systems for supporting families at psychosocial risk. Second, following European recommendations, family services are currently being delivered by institutions that are close to citizens (Council of Europe, 2011). However, governments should be vigilant, so as to ensure that the prevalence of decentralised systems with a high level of involvement by local and regional services does not result in fragmentation (Janta, 2013). Thus, coordination of family support services at an inter-country level currently constitutes an important challenge (Daly et al., 2015).

In addition to the role played by public agencies, the results obtained in this study highlight NGOs as core organisations for supporting at-risk families in Europe. As previous studies have shown, austerity policies after the recent economic recession have weakened public family-support services in several European countries (Frazier \& Marlier, 2012). Consequently, significant variations have emerged in family support funding, leading to a greater role being played by volunteers, NGOs and private companies (Janta, 2013). However, this positive facet also poses certain risks, since private interests can direct family support services, relegating supervision by stakeholders responsible for social policies to the sidelines (Boddy et al., 2011).

If we look at how family support initiatives are implemented across European countries, we find great diversity. For example, southern and eastern European countries 
(e.g., Hungary, Italy, Latvia) have a more targeted-approach to risk profiles than other countries which cover a wider range of psychosocial risks (e.g., Belgium or Sweden). It seems that differences in target populations are also related to delivery format. Thus, those countries that cover a broader range of family risk levels also tend to include group formats. This is not surprising, as group interventions have been identified as the most suitable for early prevention (Haggerty \& Shapiro, 2013). Similarly to previous studies, our results support the idea that cross-national diversity in the risk-level of the target population may in part be due to different historical traditions in relation to child welfare policy and practice (Boddy et al., 2011). Thus, those countries with 'social democratic' welfare systems and family orientation services adopt a more preventive approach in which the state assumes responsibility for supporting all families (Gilbert, 2012).

In addition to the underlying diversity of social welfare policies, the way in which family support is conceptualised also helps explain differences in the contents, methodology and theoretical models guiding the interventions. The ecologic-systemic perspective was the most prevalent theoretical base. This is not surprising, as this perspective is widespread nowadays in the family arena (Bornstein, 2015; Cox \& Paley, 2003). What may be a matter of concern, however, is that one third of the experts reported that family support interventions were not guided by any theoretical model. In our opinion, this result highlights the need for specific training for family support workers (Dodge, 2011). Parental practices were the most salient topic as far as intervention contents were concerned. This is consistent with previous literature on parental education programmes (Bennett, Barlow, Huband, Smailagic, \& Roloff, 2013). Finally, the methodologies reported were very heterogeneous, probably because of the wide range of formats and contents.

The results regarding the family support workforce are particularly interesting. The most common professions were psychologist and social worker, although other profiles emerged also (such as education and health workers, for example). This diversity underscores the complexity of family support, which is an interdisciplinary field with a multi-professional workforce (Frost et al., 2015).

The analysis of quality standards for family support initiatives targeted at families in situations of psychosocial risk revealed both strengths and weaknesses. On the one hand, standards concerning cultural validity and certain levels of manualisation were identified as being met in most European countries, and experts also reported that almost half of all countries complied with international evidence-based programme criteria (Asmussen, 2011; Bernal \& Adames, 2017; Flay et al., 2005; Gottfredson et al., 2015; Yarbrough, Shulha, Hopson, \& Caruthers, 2011). On the other hand, evidence regarding the effectiveness of the programmes continues to be a challenge. Participants' responses indicate that only two countries enforce rigorous, comprehensive programme evaluation. Non-rigorous evaluation tends to be the rule, with emphasis on coverage data and client satisfaction. These results are consistent with those reported in relation to universal family support initiatives, in which formal evaluations are uncommon (Bennett et al, 2013; Lundahl, Nimer, \& Parsons, 2006). Part of the explanation lies in the association between non-rigorous evaluation and low levels of manualisation. At the opposite end of the scale, comprehensive evaluations are the norm in standardised programmes, although these programmes are not common in the field of family support (Daly et al., 2015; Rodrigo et al., 2016). In sum, although our results point towards some advances in quality standards, family support services in Europe require a more advanced evidence-based approach, offering practitioners effective programmes that 
will have a real impact on families' lives. As reported here, partnerships with academia constitute a valuable way of making progress in this area (Long, 2016).

\section{Study limitations}

This study conducted a broad, in-depth review of how formal support is currently being delivered to at-risk families in Europe. While the results reported are interesting, the study has several limitations which should be pointed out. The rigorous criteria employed to recruit participants helped us to obtain a panel of experts with comprehensive expertise in the field. However, despite the rigor of this method, we should bear in mind that the study only considered the perspective of a single type of informant. Further studies should include a wider range of perspectives, gathering insights from practitioners, politicians and managers responsible for both public and private institutions (Law, Plunkett, Taylor, \& Gunning, 2009). On this point, the voices of service recipients, i.e. the families themselves, should also be heard. For evidencebased practice, agencies need to integrate the best available knowledge about what works according to families' expectations, values and skills (Tilbury, Osmond, \& Crawford, 2010). Moreover, from an ethical point of view, giving a voice to families means recognising them as citizens with rights to equity, representation and participation (Ayala-Nunes, Jiménez, Hidalgo, \& Jesus, 2014). A broad range of participating countries was obtained, with southern, northern, eastern and western countries represented in the sample. Nevertheless, nine countries are missing from the study, thereby reducing the impact of its conclusions. Future research should make a special effort to include informants from these countries, in order to gain a more complete picture of family support for at-risk families throughout the entire continent.

\section{Conclusions}

The targeted-expert approach adopted in the study enabled us to compile a rich, intraand inter-country overview from reliable information sources. The results obtained have several practical implications for family policy and delivery. Family support encompasses much more than parent education programmes, and initiatives for families at risk should include a mixture of services and interventions. Here, the current challenge is how to diversify services in accordance with the principles of progressive universalism (Molinuevo, 2013). In practical terms, family support initiatives should strive to meet families' specific needs, in keeping with their psychosocial risk profiles (Rodrigo et al., 2016). Therefore, services need to be diversified in terms of both intensity and delivery. Moreover, a greater focus is required on preventive initiatives, since these represent the most effective and least stigmatising form of delivery (Haggerty \& Shapiro, 2013).

Despite advances in supporting at-risk families, ensuring an evidence-based approach remains a challenge for most European countries. In order for progress to be made in this sense, two areas of action have been highlighted in this study which should be included in the policy agenda of European countries: the evidence-based arena and a framework for standardising practitioner skills. There is a need for rigorous evaluations to identify what works, for whom and under what circumstances. This move towards evidence-based programmes should be counterbalanced with the testing of innovative and promising practices (Moran et al., 2004). Moreover, in addition to being rigorous, evaluations also need to be useful, feasible, suitable and accountable (Yarbrough et al., 2011). In sum, family support research needs to be practice-based, which requires a pluralist approach to evidence (Fives, Canavan, \& Dolan, 2014). Agreement is also needed regarding the skills and qualifications of the family support workforce, in order 
to ensure quality performance when attending families (Durlak \& DuPre, 2008). Hence, progress is required to make the best training practices available to practitioners working in this field (Long, 2016).

To overcome the problems highlighted above, there is a need for policy changes at both a national and a European level. At a national level, a comprehensive multidisciplinary approach is required, in which researchers, practitioners, managers and policy makers are connected locally, regionally and nationally in order to ensure informed family support delivery. This inter-connected approach should also listen to the voices of children and families. Moreover, a supranational framework should be established to provide policy advice at a European level. This framework should be based on the existing structures for family support policy at a national level, in order to build upon the diversity of European countries. To conclude, the updated review offered in this paper may serve as a first step towards building a common family support framework at a European level, which would encompass family support and parenting policies guided by common cross-national goals and values, while at the same time respecting the specificities of individual cultural and family contexts. 


\section{References}

Asmussen, K. (2011). The evidence-based parenting practitioner's handbook. New York: Routledge.

Ayala-Nunes, L., Jiménez, L., Hidalgo, V., \& Jesus, S. (2014). Family feedback in Child Welfare Services: A systematic review of measures. Children and Youth Services Review, 44, 299-306. http://dx.doi.org/10.1016/j.childyouth.2014.07.004

Axford, N., Elliott, D.S., \& Little, M. (2012). Blueprints for Europe: Promoting evidence-based programmes in children's services. Psychosocial Intervention, 21(2), 205-14. https://doi.org/10.5093/in2012a11

Babbie, E. (2004). The practice of social research. Belmont, CA: Wadsworth.Boddy, J., Smith, M., \& Statham, J. (2011). Understandings of efficacy: Cross-national perspectives on 'what works' in supporting parents and families. Ethics and Education, 6, 181-196. http://dx.doi.org/10.1080/17449642.2011.622992

Bennett, C., Barlow, J., Huband, N., Smailagic, N., \& Roloff, V. (2013). Group-based parenting programs for improving parenting and psychosocial functioning: A systematic review. Journal of the Society for Social Work and Research, 4(4), 300-332. http://dx.doi.org/10.5243/jsswr.2013.20

Bernal, G., \& Adames, C. (2017). Cultural adaptations: Conceptual, ethical, contextual and methodological issues for working with ethnocultural and majority-world populations. Prevention Science, 18, 681-688. http://dx.doi.org/10.1007/s11121-0170806-0

Boddy, J., Smith, M., \& Statham, J. (2011). Understandings of efficacy: Cross-national perspectives on 'what works' in supporting parents and families. Ethics and Education, 6, 181-196. http://dx.doi.org/10.1080/17449642.2011.622992

Boddy, J., Statham, J., Smith, M., Ghate, D., Wigfall, V., Hauari, H., Canali, C. et al. (2009). International perspectives on parenting support: Non-English language sources. DCSF Research Report No. DCSF-RR114. Nottingham: DCSF.

Bornstein, M.H. (2015). Children's parents. In M.H. Bornstein and T. Leventhal (Eds.), Handbook of Child Psychology and Developmental Science. Vol. 4. Ecological Settings and Processes. New Jersey: Wiley.

Cartwright, N., \& Hardie, J. (2012). Evidence-based policy. A practical guide to doing it better. New York: Oxford University Press.

ChildOnEurope (2007). Survey on the role of parents and the support from the Governments in the EU. Florence, Italy: ChildONEurope.

Council of Europe (2006). Recommendation Rec(2006)19 of the Committee of Ministers to members states on policy to support positive parenting. Available at Council of Europe: http://www.coe.int/es (Accessed: 21 April 2016).

Council of Europe (2011). Recommendation Rec(2011)12 of the Committee of Ministers to member states on children's rights and social services friendly to children and families. Available at Council of Europe: http://www.coe.int/es (Accessed: 21 April 2016).

Cox, M. J., \& Paley, B. (2003). Understanding families as systems. Current Directions in Psychological Science, 12(5), 193-196. http://dx.doi.org/10.1111/1467-8721.01259 
Daly, M., Bray, R., Bruckauf, Z., Byrne, J., Margaria, A., Pec'nik, N., \& SammsVaughan, M. (2015). Family and Parenting Support: Policy and Provision in a Global Context. Innocenti Insight, UNICEF Office of Research, Florence.

Dillmann, D. A. (2000). Mail and internet surveys: The tailored design method. New York: John Wiley and Sons.

Dodge, K. A. (2011). Context matters in child and family policy. Child Development, 82(1), 433-442. http://dx.doi.org/10.1111/j.1467-8624.2010.01565.x

Durlak, J. A., \& DuPre, E. P. (2008). Implementation matters: A review of research on the influence of implementation on program outcomes and the factors affecting implementation. American Journal of Community Psychology, 41, 327-350. http://dx.doi.org/10.1007/s10464-008-9165-0

European Commission (2013) European Commission Recommendation of 20 February 2013 on Investing in children: breaking the cycle of disadvantage (2013/112/EU). Available at EUR-lex Access to European Union Law: http://eurlex.europa.eu/homepage.html (Accessed: 21 April 2016).

European Social Network (2012). Family and parenting support. The role of public services. ESN survey on family and parenting support. Retrieved from www.esneu.org/raw.php?page $=$ files\&id $=417$

Fives A., Canavan J., \& Dolan P. (2014). Evaluation study design. A pluralist approach to evidence. Galway: UNESCO.

Flay, B., Biglan, A., Boruch, R. F., González, F., Gottfredson, D., Kellam, S., et al. (2005). Standards of evidence: Criteria for efficacy, effectiveness and dissemination. Prevention Science, 6(3), 151-175. https://doi.org/10.1007/s11121-015-0555-x

Fleiss, J. L. (1971). Measuring nominal scale agreement among many raters. Psychological Bulletin, 16(5), 378-382. https://doi.org/10.1037/h0031619

Frazier, H., \& Marlier, E. (2012). Current situation in relation to child poverty and child well-being: EU policy context, key challenges ahead and ways forward. Network of Independent Experts on Social Inclusion. Brussels: European Commission.

Frost, N., Abbott, S., \& Race, T. (2015): Family support. Cambridge: Polity.

Gilbert, N. (2012). A comparative study of child welfare systems: Abstract orientations and concrete results. Children and Youth Services Review, 34, 532-536. https://doi.org/10.1016/j.childyouth.2011.10.014

Gottfredson, D.C., Cook, T.D., Gardner, F.E, Gorman-Smith, D., Howe, G.W., Sandler, I.N., \& Zafft, K.M. (2015). Standards of evidence for efficacy, effectiveness, and scaleup research in prevention science: next generation. Prevention Science, 16(7), 893-926. https://doi.org/10.1007/s11121-015-0555-x.

Haggerty, K. P., \& Shapiro, V. B. (2013). Science-based prevention through communities that care: A model of social work practice for public health. Social Work in Public Health, 28, 349-365. http://dx.doi.org/10.1080/19371918.2013.774812

Janta, B. (2013). Parenting support policy brief. Santa Monica: RAND.

Law, J., Plunkett, C., Taylor, J., \& Gunning, M. (2009). Developing policy in the provision of parenting programmes: integrating a review of reviews with the perspectives of both parents and professionals. Child: care, health and development 35 , 302-312. http://dx.doi.org/10.1111/j.1365-2214.2009.00939.x 
Long, N. (2016). Future trends in parenting education. In J. Ponzetti (Ed). Evidencebased parenting education: A global perspective (pp. 311-328). New York: Routledge.

Lundahl, B. W., Nimer, J., \& Parsons, B. (2006). Preventing child abuse: A metaanalysis of parent training programs. Research on Social Work Practice, 16(3), 251262. http://dx.doi.org/10.1177/1049731505284391

Molinuevo, D. (2013). Parenting support in Europe. Dublin: Eurofound.

Moran, P., Ghate, D., \& van der Merwe, A. (2004) What Works in Parenting Support? A Review of the International Evidence. Research Report RR574.

Randolph, J. J. (2008). Online Kappa Calculator [Computer software]. Retrieved from http://justus.randolph.name/kappa

Rodrigo, M.J., Almeida, A., \& Reichle, B. (2016). Evidence-based parent education programs: A European perspective. In J. Ponzetti (Ed). Evidence-based parenting education: A global perspective (pp. 85-104). New York: Routledge.

Rodrigo, M.J., Byrne, S., \& Álvarez, M. (2012). Preventing child maltreatment through parenting programmes implemented at the local social services level. European Journal of Developmental Psychology, 9(1), 89-103. http://dx.doi.org/10.1080/17405629.2011.607340

Tilbury, C., Osmond, J., \& Crawford, M. (2010). Measuring client satisfaction with child welfare services. Journal of Public Child Welfare, 4(1), 77-90.

Thomas, J., \& Harden, A. (2008). Methods for the thematic synthesis of qualitative research in systematic reviews. BMC Medical Research Methodology, 8, 8-45. http://dx.doi.org/10.1186/1471-2288-8-45

United Nations General Assembly. (1989). Convention on the Rights of the Child. Retrieved from http://www.ohchr.org/documents/professionalinterest/crc.pdf

Yarbrough, D.B, Shulha, L.M., Hopson, R.K., \& Caruthers, F.A. (2011, 3rd edition). The program evaluation standards. California: Sage. 
Figure 1. Participating countries in the study

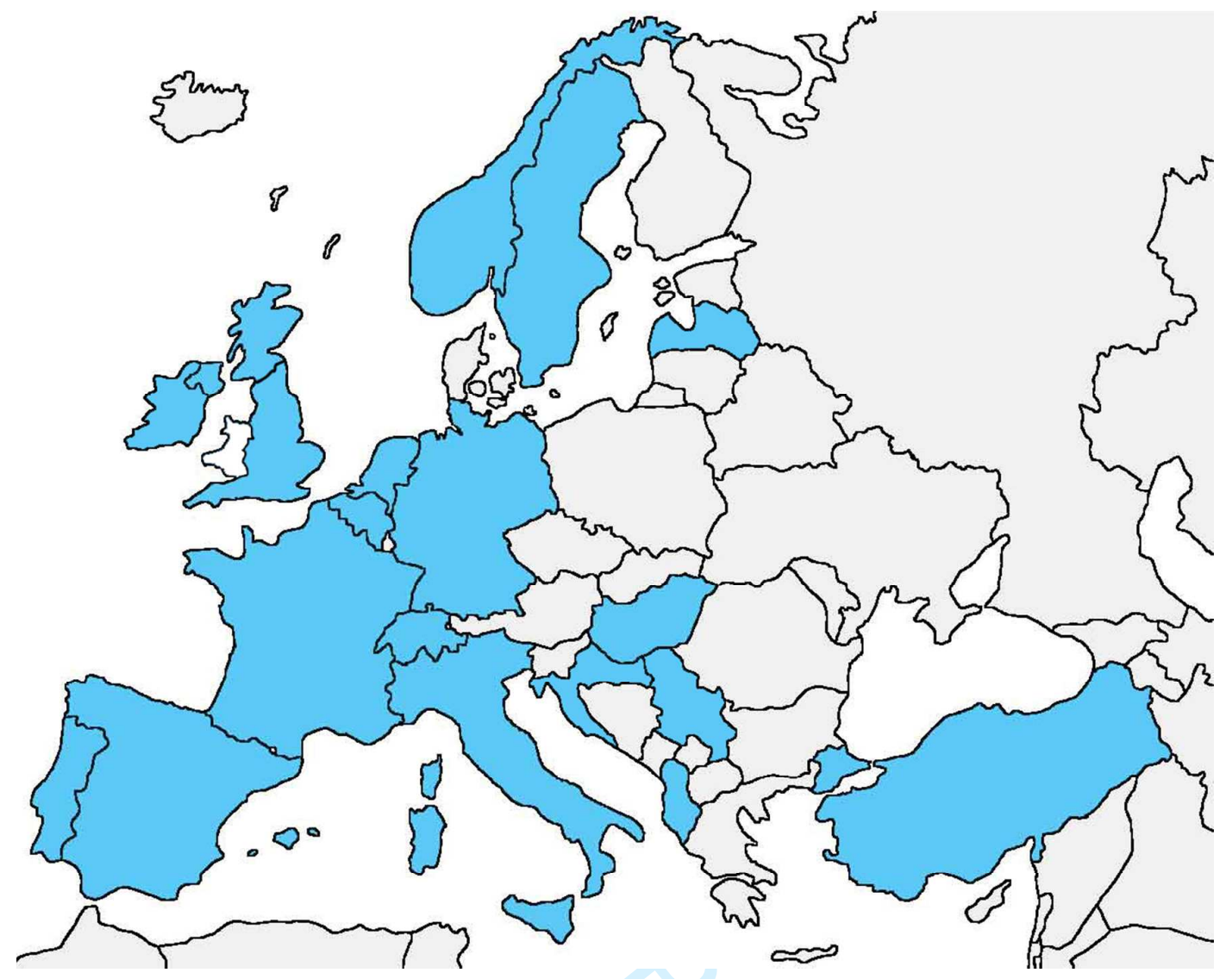

Participating countries: Albania, Belgium, Croatia, England, France, Germany, Hungary, Ireland, Italy, Norway, Portugal, Republic of Latvia, Republic of Serbia, Scotland, Spain, Sweden, Switzerland, The Netherlands, and Turkey.

Non-participating countries 
Figure 2. Theoretical models that guided the interventions

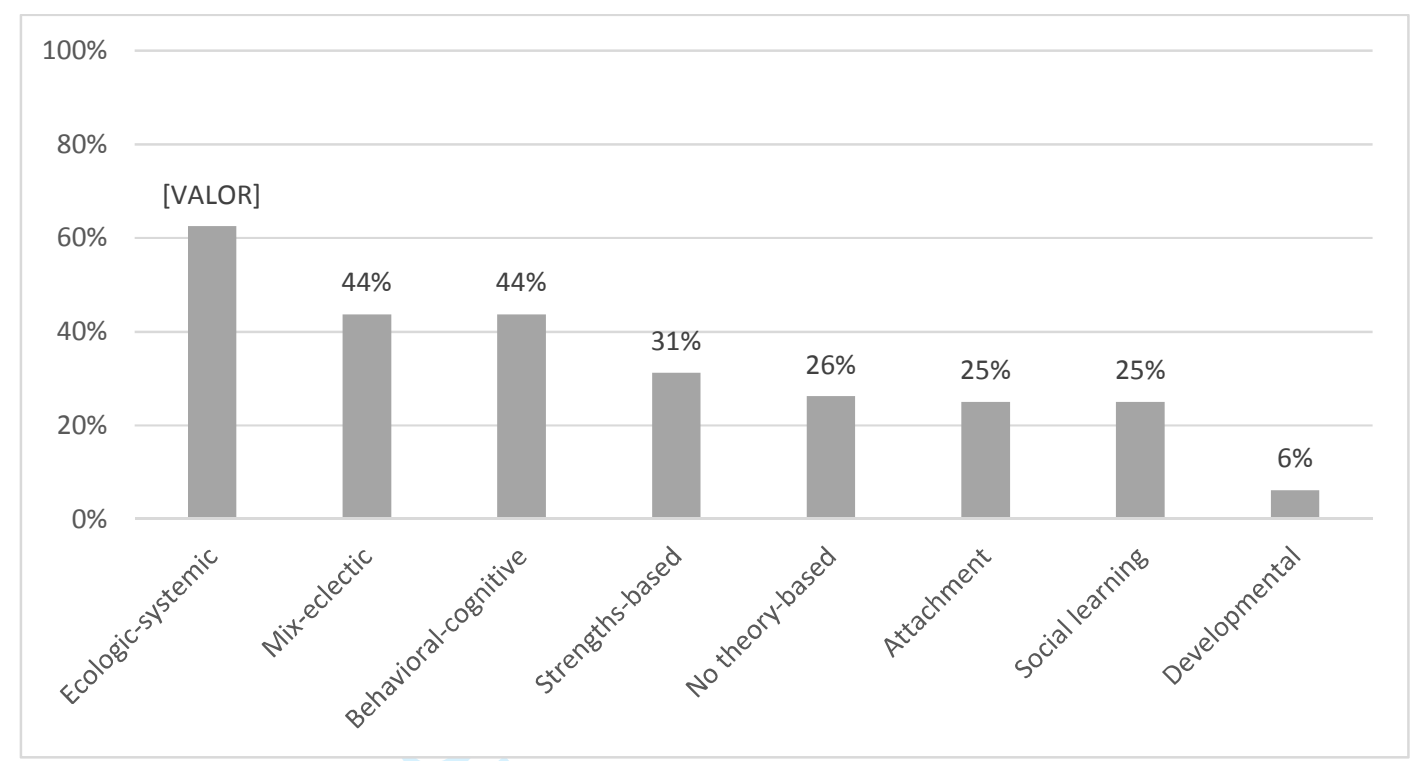


Table 1. Service providers profile by country

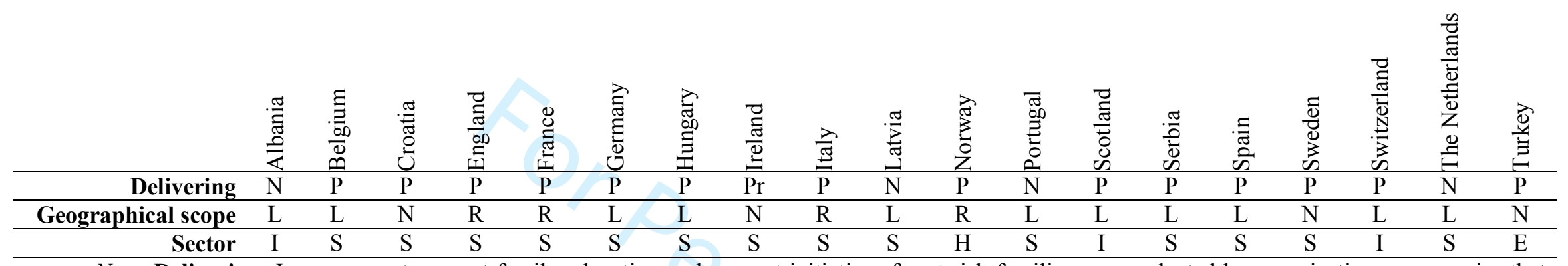

Note. Delivering: In your country, most family education and support initiatives for at-risk families are conducted by organizations or agencies that are: Public (P); Private (Pr); Non-profit sector (e.g., foundations, associations, etc.) (N). Geographical scope: Regarding the geographical scope, these organizations/agencies are usually: National (N); Regional (R); Local (L). Sector: Most organizations/agencies in charge of the interventions come from the areas of: Social Services / Welfare (S); Health (H); Education (E); Inter-sectorial (I). 
Table 2. Intervention characteristics by country

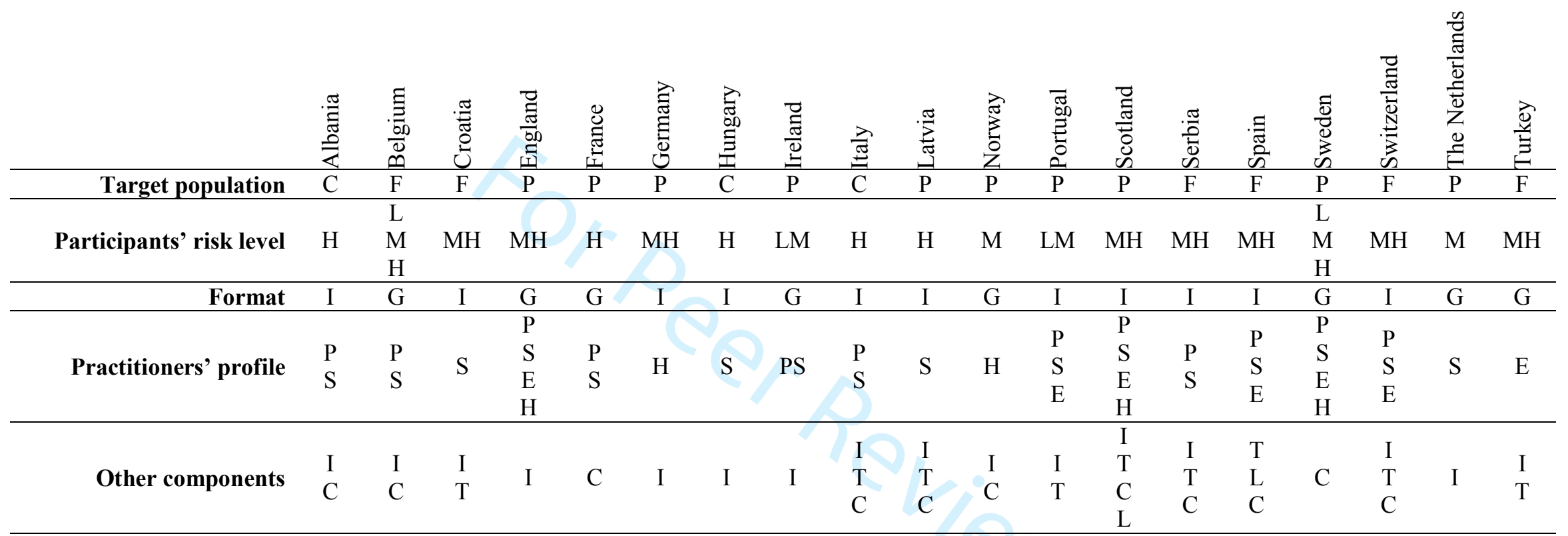

Note. Target population: In general terms, these interventions are aimed at: Parents (P); Children (C); The whole family (F). Participants' risk level: The participants' risk levels are mostly: Low (L); Low-medium (L-M); Medium (M); Medium-high (M-H); High (H); Low-medium-high (L-M-H).

Format: Generally, these interventions are conducted at the following level: Individual (e.g., home-based family intervention) (I); Group (e.g., parent education groups) (G); Community (e.g., TV awareness campaign) (C). Practitioners' profile: The practitioners that apply these interventions are usually (tick all pertinent options): Psychologists (P); Social workers (S); Education staff (E); Health staff (H); Others (0). Other components: Besides their educational component, these interventions usually also have the following component (tick all pertinent options): Tangible (material aid) (T); Informational and guidance (I); Therapeutic or counselling (C); Leisure time (L); Others (0). 
Table 3. Quality standards by country

\begin{tabular}{|c|c|c|c|c|c|c|c|c|c|c|c|c|c|c|c|c|c|c|c|}
\hline & $\begin{array}{l}\stackrel{\pi}{\Xi} \\
\stackrel{\Xi}{\mathbb{Z}}\end{array}$ & 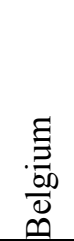 & $\begin{array}{l}. \frac{\pi}{\pi} \\
\stackrel{\Xi}{U} \\
\text { U }\end{array}$ & $\begin{array}{l}\overrightarrow{\widetilde{J}} \\
\vec{\Xi} \\
\overrightarrow{00} \\
\vec{\omega}\end{array}$ & 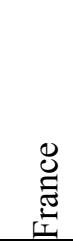 & 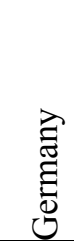 & 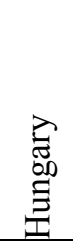 & $\frac{\vec{\Xi}}{\stackrel{\Xi}{\Xi}}$ & 齐 & 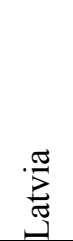 & 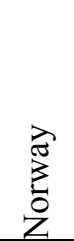 & 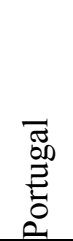 & 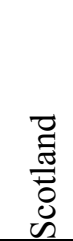 & $\begin{array}{l}\frac{\pi}{0} \\
\overline{0} \\
\mathscr{D}\end{array}$ & $\begin{array}{l}\text { ज्ञ } \\
\text { की }\end{array}$ & $\begin{array}{l}\frac{\tilde{D}}{0} \\
\frac{0}{0} \\
\text { bे }\end{array}$ & 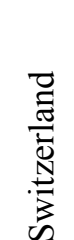 & 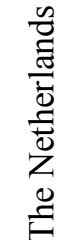 & 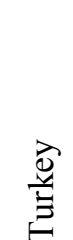 \\
\hline Evidence-based programmes & $\mathrm{N}$ & $\overline{\mathrm{N}}$ & $\mathrm{N}$ & $\bar{C}$ & $\overline{\mathrm{N}}$ & $\mathrm{N}$ & $\vec{C}$ & $\mathrm{C}$ & $\vec{C}$ & $\overline{\mathrm{N}}$ & $\overrightarrow{\mathrm{C}}$ & $\overline{\mathrm{N}}$ & $\mathrm{C}$ & $\mathrm{C}$ & $\mathrm{N}$ & $\mathrm{C}$ & $\mathrm{N}$ & $\mathrm{N}$ & $\mathrm{N}$ \\
\hline Manualisation & $\mathrm{N}$ & IM & IM & $\mathrm{M}$ & IM & IM & $\mathrm{M}$ & $\mathrm{M}$ & $\mathrm{M}$ & IM & $\mathrm{M}$ & IM & $\mathrm{M}$ & IM & IM & $\mathrm{M}$ & IM & IM & $\mathrm{M}$ \\
\hline Cultural validity & $\mathrm{N}$ & $\mathrm{C}$ & $\mathrm{C}$ & $\mathrm{F}$ & $\mathrm{C}$ & $\mathrm{C}$ & $\mathrm{A}$ & $\mathrm{A}$ & $\mathrm{C}$ & $\mathrm{C}$ & $\mathrm{A}$ & $\mathrm{C}$ & $\mathrm{C}$ & $\mathrm{C}$ & $\mathrm{C}$ & A & A & A & $\mathrm{C}$ \\
\hline
\end{tabular}

Note. Evidence-based programmes: Overall, these interventions: Comply with the criteria of evidence-based programmes (C); Do not comply with the criteria of evidence-based programmes (N). Manualisation: Generally speaking, these interventions: Have complete and detailed manuals (in which the previous aspects are mentioned) (M); Have incomplete manuals or some written materials (IM); Do not have any manual or written materials (N). Cultural validity: When manualized, most of these interventions are: Designed in the country (C); Foreign but culturally adapted programmes (A); Foreign programmes with no cultural adaptation (F); There are no manualized family education and support programmes for at-risk families in the country $(\mathrm{N})$. Evidence of effectiveness: These interventions have been mostly: Rigorously evaluated (R); Evaluated but in a non-rigorous manner (NR); Not evaluated (NE). Partnerships with academia: If any evidence-based family education and support programme exist for at-risk families, in most cases: Partnerships with universities have been conducted (P); Partnerships with universities have not been conducted (NP); No evidence-based programme is applied with at-risk families in this country (A). 


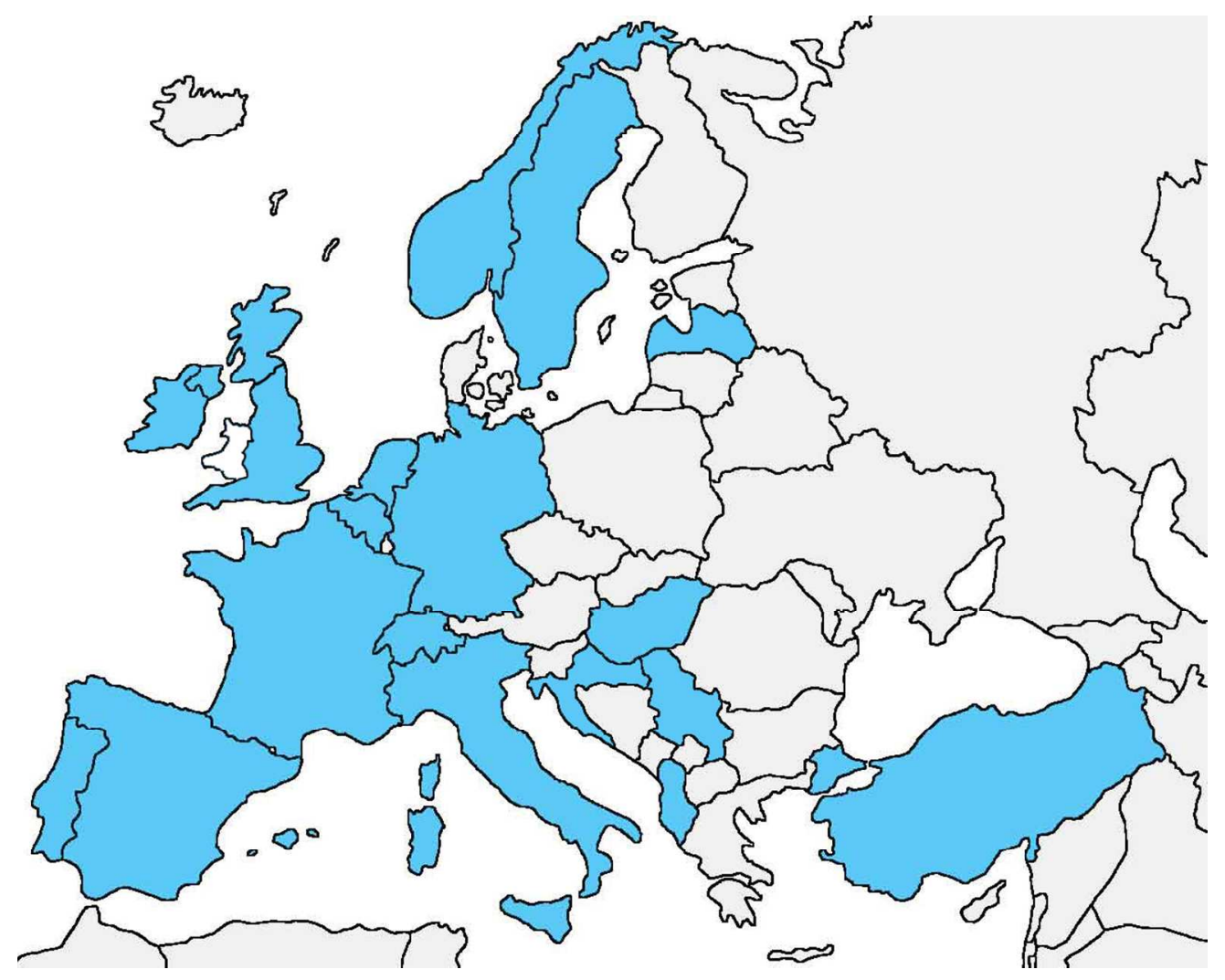

Figure 1

$451 \times 361 \mathrm{~mm}(72 \times 72 \mathrm{DPI})$ 


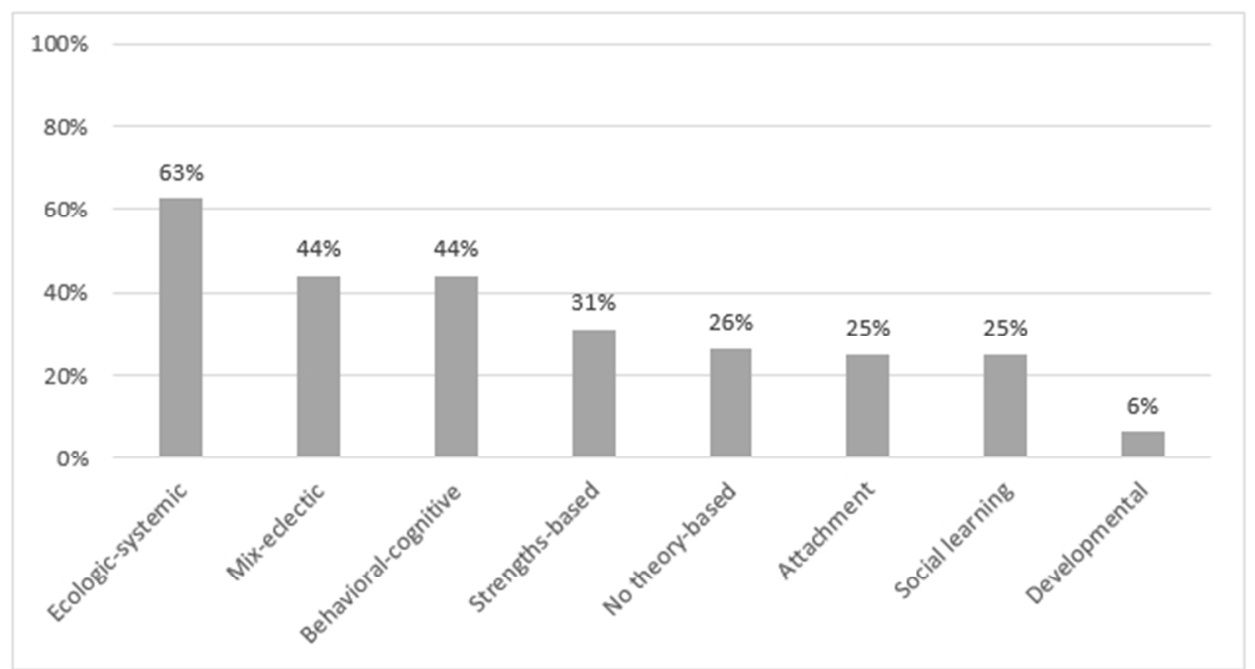

Figure 2. Theoretical models that guided the interventions 